\title{
Facility FDA Establishment Identifier
}

National Cancer Institute

\section{Source}

National Cancer Institute. Facility FDA Establishment Identifier. NCI Thesaurus. Code C134004.

A unique identifier assigned by the Food and Drug Administration (FDA) to track inspections of a regulated establishment or facility. They are also used to track generic drug user fee acts (GDUFA) facility fee payments. 